\title{
Role of Magnetic Resonance Imaging in Breast Cancer: Detection of Tumor Response Post Neoadjuvant Chemotherapy
}

\author{
TALAL A. AMER, M.D.*; MOHAMED A. HEGAZY, M.D.**; GHADA H. ABDELRAOUF, M.Sc.* and \\ FATMA M. SHERIF, M.D.* \\ The Departments of Diagnostic Radiology* and Surgical Oncology**, Faculty of Medicine, Mansoura University
}

\begin{abstract}
Background: This study aimed at assessment of the role of magnetic resonance imaging (MRI) in evaluating residual disease, and its ability to detect response after neoadjuvant chemotherapy (NAC) for locally advanced breast cancer cases.

Aim of Study: The aim of this study was to assess the role of MRI in evaluating response to NAC for locally advanced breast cancer cases.

Patients and Methods: This prospective study included 40 female patients with pathologically proven locally advanced breast cancer, with mean age of 43.1 years. They underwent dynamic MRI with diffusion study after neoadjuvant chemotherapy (NAC) to assess the response after the NAC, results were compared to the histopathological results after surgery following NAC as the gold standard. The study was done at Radiology Department, Mansoura University, Egypt. This study was carried out in the period between February 2017, and September 2019.

Results: MRI showed sensitivity of $91.2 \%$, specificity $66.7 \%$, PPV $93.9 \%$, NPV $57.1 \%$, and accuracy $87.5 \%$ in assessment of the response to NAC. In (17.5\%) of cases MRI showed overestimation compared to the pathological results. In $(5 \%)$ of cases MRI showed underestimation compared to the pathological results.
\end{abstract}

Conclusion: MRI proved to be highly beneficial in assessment of response of locally advanced breast cancer to NAC. However, it may overestimate or underestimate residual disease in some patients. Further studies to improve the specificity of MRI may be of benefit.

Key Words: Neoadjuvant chemotherapy-MRI-Response - Residual disease - Locally advanced breast cancer.

\section{Introduction}

BREAST cancer is the most common cancer in women. It accounts for $27 \%$ of all female cancers. If breast cancer is diagnosed at an early stage,

Correspondence to: Dr. Talal A. Amer, The Department of Diagnostic Radiology, Faculty of Medicine,

Mansoura University there is a good chance of cure. The more advanced the cancer, the more it has grown, and spread [1].

Improvements in diagnosis of breast cancer are largely responsible for increasing rate of survival among breast cancer women [2]. Breast cancer mortality has declined since 1990, and this can be attributed to early detection through screening mammography, and improved therapy [3] .

Pre-operative or neoadjuvant chemotherapy (NAC) has gained a real accepted and underlying role in treatment of stage II and III breast cancer [4]. Obviously, the most significant effect of this treatment is its potential to clear the neoplastic tissue completely from the breast and axillary region. Complete response makes the conservative surgery feasible with an improved expected survival

The role of magnetic resonance imaging (MRI) in cases of NAC is crucial. During NAC, it allows evaluation of the therapeutic response. Thus, monitoring of the response allows the type of chemotherapy to be changed if the tumor does not shrink, or the chemotherapy to be interrupted if the tumor progresses. At the end of the treatment, the therapeutic response can be described. This response is an important prognostic factor as a complete response is associated with disease-free and overall survival benefit [6].

\section{Patients and Methods}

This prospective study included 40 female patients with pathologically proven locally advanced breast cancer by "tru- cut" biopsy. Their ages ranged from 26 to 68 years, with the mean age of 43.1 years. This study was carried out in the period between February 2017, and September 2019. All patients underwent dynamic MRI with 
diffusion study after NAC to assess the tumor response,results were compared to the histopathological results after surgery following NAC as the gold standard. Patients with contraindication to MRI examination (e.g. patients with cardiac pacemaker), and patients without histopathological results following surgery were excluded from the study.

Dynamic contrast-enhanced breast MRI with diffusion study of all patients was performedwith a 1.5 Tesla MRI device (Philips Ingenia, Best, Netherland). All patients were examined in the prone position using dedicated breast coil. Alocalizer sagittal scout view was obtained, axial non fat-saturated TIWI was obtained by FSE with the following imaging parameters: TR 450ms, TE $14 \mathrm{~ms}$, slice thickness $3 \mathrm{~mm}$, field of view (FOV) $300-360 \mathrm{~mm}$ and matrix was $307 \times 512$. STIRsequence was obtained with the following parameters: TR 7000-9000ms, TE 70ms \& inversion time (TI) was $150 \mathrm{~ms}$, slice thickness was $3-4 \mathrm{~mm}$ with inter slice gap $1 \mathrm{~mm}$, field of view (FOV) $300-360 \mathrm{~mm}$ and the matrix was $307 \times 512$. T2WI pulse sequence was obtained Using FSE with the following imaging parameters TR $2000 \mathrm{~ms}$, TE $8 \mathrm{~ms}$, slice thickness $80 \mathrm{~mm}$, field of view (FOV) $400-500 \mathrm{~mm}$, and matrix was $256 x 256$, filp angel 90 degree to obtain axial non-fat saturated T2WI.

Diffusion weighted imaging (DWI) was done before contrast administration by a multisection single shot spin echo EPI sequence with TR/TE/ NEX: $5800 / 139 \mathrm{~ms} / 1$ with $b$ values $=0,500$, and $1000 \mathrm{~mm}^{2} / \mathrm{sec}$. The diffusion gradients were applied sequentially in the three orthogonal directions $(X$, $\mathrm{Y}, \& \mathrm{Z}$ directions). Sections of $4 \mathrm{~mm}$ thickness, interslice gap of $1 \mathrm{~mm}$, a $300-360 \mathrm{~mm}$ FOV, and a $128 \times 256$ matrix were used for all images. The total acquisition time was $120 \mathrm{sec}$. Orthogonal (DWI) images \& ADC maps were obtained in all cases.

Then,dynamiccontrast enhanced MR studies were made in the axial plane with fat suppression by applying fat saturated pulse. A bolus of gadolinium based contrast agent in a dose of $0.2 \mathrm{mmol} /$ $\mathrm{Kg}$ was injected intravenously with an automatic injector at a rate of $3-5 \mathrm{ml} / \mathrm{s}$, followed by $20 \mathrm{ml}$ saline flush. The sequence used was FLASH 3 D GRE-T $1 \mathrm{~W} 1$ with the following parameters: TR 4$8 \mathrm{~ms}$, TE $2 \mathrm{~ms}$, flip angle 20-25 degrees, slice thickness $2 \mathrm{~mm}$ with no inter-slice gap, field of view (FOV) 300-360mm, and the matrix was 307 X 512. Dynamic study consists of one pre contrast, and 5 post contrast series, each of them took about $1.15 \mathrm{~min}$ with a break between the pre contrast, and post contrast study about 20 sec.
Upon completion of imaging, image post processing and image analysis were done including maximum intensity projection (MIP) images, and subtraction images were created by using the Standard subtraction function of the device that subtracts early and late contrast-enhanced images from noncontrast images. The time signal intensity curves of the images were created.

The resulting data were analyzed using Statistical Package for Social Science version 22 (IBM SPSS Inc. released 2013, Chicago, Ill, USA). Qualitative data were reported using number and percent. Quantitative data were described using median (minimum and maximum) for nonparametric data and mean, standard deviation for parametric data. The obtained results were considered significant at $p$-value $\leq 0.05$. Receiver Operator Characteristic (ROC) curve analysis was performed to detect validity of MR findings compared to histopathology as the reference standard. Sensitivity and specificity were detected from the curve, positive predictive value (PPV), negative predictive value (NPV) and accuracy were calculated through cross tabulation.

\section{Results}

This prospective study included 40 female patients with pathologically proven locally advanced breast cancer. Their ages ranged from 26 to 68 years with the mean age of $43.1 \pm 10.18$ SD years. In our study, the premenopausal age category was the predominating, representing $75 \%$ of the studied cases. All patients underwent "Tru-cut" biopsy for diagnosis of the pathological type. The most common pathological type of breast cancer in this study was the "invasive duct carcinoma", that represented $65 \%$ of the studied cases.

On MRI, eight patients (20\%) showed complete response to the NAC, 25 patients $(62.5 \%)$ showed partial response (Fig. 2). Two patients (5\%) showed stable course, and 5 patients (12.5\%) showed progressive course. Table () demonstrated MR findings in the examined group. Diffusion-weighted MR study was performed in 31 patients. As regard cases with partial response, $44 \%$ of themrevealed restricted diffusion, and 52\% declared non restricted diffusion. The time signal intensity curve was also applied in 31 patients. Three cases $(9.7 \%)$ showed type 1 cuve "Rising curve", 18 cases $(58.1 \%)$ showed type 2 curve "Plateau curve", and 10 cases (32.3\%) showed type 3 curve "Washout curve" (Table 1). 
Pathological assessment following the NAC revealed with 11 patients $(27.5 \%)$ complete response, 23 patients $(57.5 \%)$ with partial response. Two cases showed stable course and four cases (10\%) showed progressive course (Table 2).

Compared to pathological results, ROC curve analysis revealed that ADC value of $0.75 \times 10^{-3}$ $\mathrm{mm}^{2} / \mathrm{s}$ can be used as a cutoff value to differentiated between presence or absence of response to NAC with sensitivity of $83.3 \%$, specificity of $80 \%$ and accuracy of $83.3 \%$ (Fig. 1, Table 3). The validity of MRI findings was analyzed with reported sensitivity of $91.2 \%$, specificity of $66.7 \%$ an accuracy of $87.5 \%$ (Table 4 ).

Table (1): MRI findings of the post NAC studied cases $(n=40)$.

\begin{tabular}{|c|c|c|}
\hline MRI & $\mathrm{N}=40$ & $\%$ \\
\hline \multicolumn{3}{|l|}{ Morphology (appearance of lesion): } \\
\hline No lesions & 4 & 10.0 \\
\hline Non mass enhancement (NME) & 6 & 15.0 \\
\hline Focal & 10 & 25.0 \\
\hline Decentralized & 18 & 45.0 \\
\hline Tiny Foci & 2 & 5.0 \\
\hline \multicolumn{3}{|l|}{ Morphology (LNs): } \\
\hline No significant & 15 & 37.5 \\
\hline Positive unilateral & 18 & 45.0 \\
\hline Positive bilateral & 7 & 17.5 \\
\hline \multicolumn{3}{|l|}{ Morphology chest wall invasion: } \\
\hline No chest wall invasion & 38 & 95.0 \\
\hline Positive chest wall invasion & 2 & 5.0 \\
\hline \multicolumn{3}{|l|}{ Morphology pattern of enhancement: } \\
\hline Heterogeneous & 23 & 57.5 \\
\hline NME & 9 & 22.5 \\
\hline Marginal thick enhancement & 2 & 5.0 \\
\hline Tiny enhancing foci & 2 & 5.0 \\
\hline No residual enhancement & 4 & 10.0 \\
\hline Diffusion: & $\mathrm{n}=31$ & \\
\hline Non restricted & 14 & 45.2 \\
\hline Restricted & 17 & 54.8 \\
\hline Time signal intensity Curve: & $\mathrm{N}=31$ & \\
\hline Type 1 & 3 & 9.7 \\
\hline Type 2 & 18 & 58.1 \\
\hline Type 3 & 10 & 32.3 \\
\hline \multicolumn{3}{|l|}{ Impression of tumor response to NAC: } \\
\hline Complete response & 8 & 20.0 \\
\hline Partial response & 25 & 62.5 \\
\hline Stable disease & 2 & 5.0 \\
\hline Progressive disease & 5 & 12.5 \\
\hline
\end{tabular}

NAC: Neoadjuvant chemotherapy.

LN : Lymph nodes.
Table (2): Pathology results of studied cases $(n=40)$.

\begin{tabular}{lcl}
\hline Pathology & $\mathrm{N}=40$ & $\%$ \\
\hline Post NAC: & & \\
$\quad$ Complete response & 11 & 27.5 \\
$\quad$ Partial response & 23 & 57.5 \\
$\quad$ No response (stable) & 2 & 5.0 \\
$\quad$ No response (progressive) & 4 & 10.0 \\
LNs: & & \\
$\quad$ Free & 18 & 45.0 \\
$\quad$ Infiltrated & 22 & 55.0 \\
\hline
\end{tabular}

Table (3): The ROC curve analysis of the validity of ADC value in assessment of the tumor response to the NAC.

\begin{tabular}{ccccccc}
\hline AUC \\
$(95 \% \mathrm{CI})$ & $\begin{array}{c}\text { Cut off } \\
\text { point }\end{array}$ & $\begin{array}{c}\text { Sensi- } \\
\text { tivity } \\
(\%)\end{array}$ & $\begin{array}{c}\text { Speci- } \\
\text { ficity } \\
(\%)\end{array}$ & $\begin{array}{c}\text { PPV } \\
(\%)\end{array}$ & $\begin{array}{c}\text { NPV } \\
(\%)\end{array}$ & $\begin{array}{c}\text { Acc- } \\
\text { uracy } \\
(\%)\end{array}$ \\
\hline ADC 0.91 & $\begin{array}{l}\leq 0.75 \times 10^{-3} \\
\mathrm{~mm}^{2} / \mathrm{s}\end{array}$ & 83.3 & 80.0 & 50.0 & 95.2 & 83.3 \\
\hline
\end{tabular}

ROC curve : Receiver operator characteristic curve.

AUC : Area under curve.

PPV : Positive predictive value.

NPV : Negative predictive value.

Table (4): Validity of MRI in detection of breast cancer response to NAC in the studied cases compared to pathology.

\begin{tabular}{|c|c|c|c|c|c|c|}
\hline & \multicolumn{2}{|c|}{ Pathology } & \multirow{2}{*}{$\begin{array}{c}\text { Sensi- } \\
\text { tivity } \\
(\%)\end{array}$} & \multirow{2}{*}{$\begin{array}{c}\text { Speci- } \\
\text { ficity } \\
(\%)\end{array}$} & \multirow{2}{*}{$\begin{array}{l}\text { PPV NPV } \\
(\%) \quad(\%)\end{array}$} & \multirow{2}{*}{$\begin{array}{c}\text { Acc- } \\
\text { uracy } \\
(\%)\end{array}$} \\
\hline & $\begin{array}{c}\text { No } \\
\text { response }\end{array}$ & $\begin{array}{l}\text { Res- } \\
\text { ponse }\end{array}$ & & & & \\
\hline \multicolumn{7}{|l|}{ MRI: } \\
\hline No response & 4 & 3 & 91.2 & 66.7 & $3.9 \quad 57.1$ & 87.5 \\
\hline Response & 2 & 31 & & & & \\
\hline
\end{tabular}

PPV: Positive predictive value. NPV: Negative predictive value.

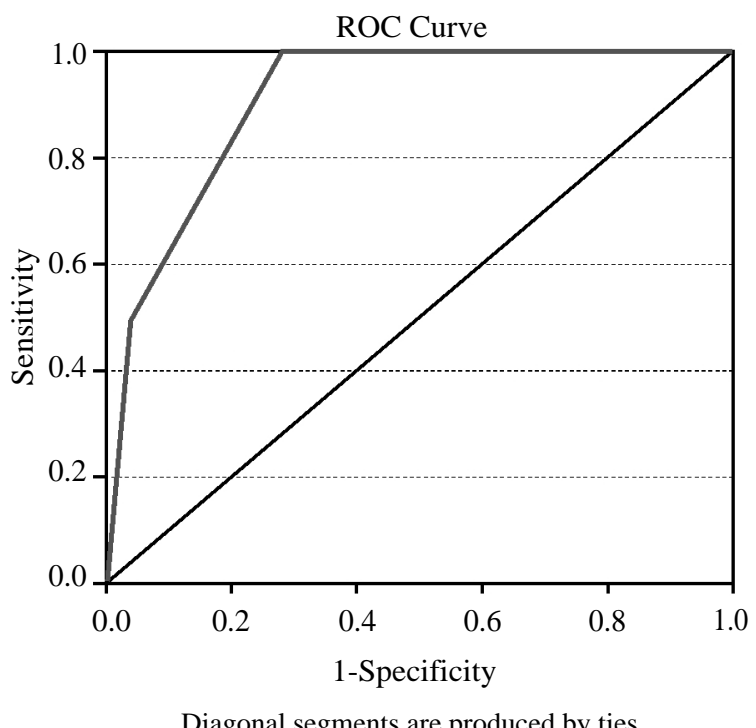

Fig. (1): The ROC curve of validity of ADC value in differentiation of breast cancer response to NAC compared to pathology. 

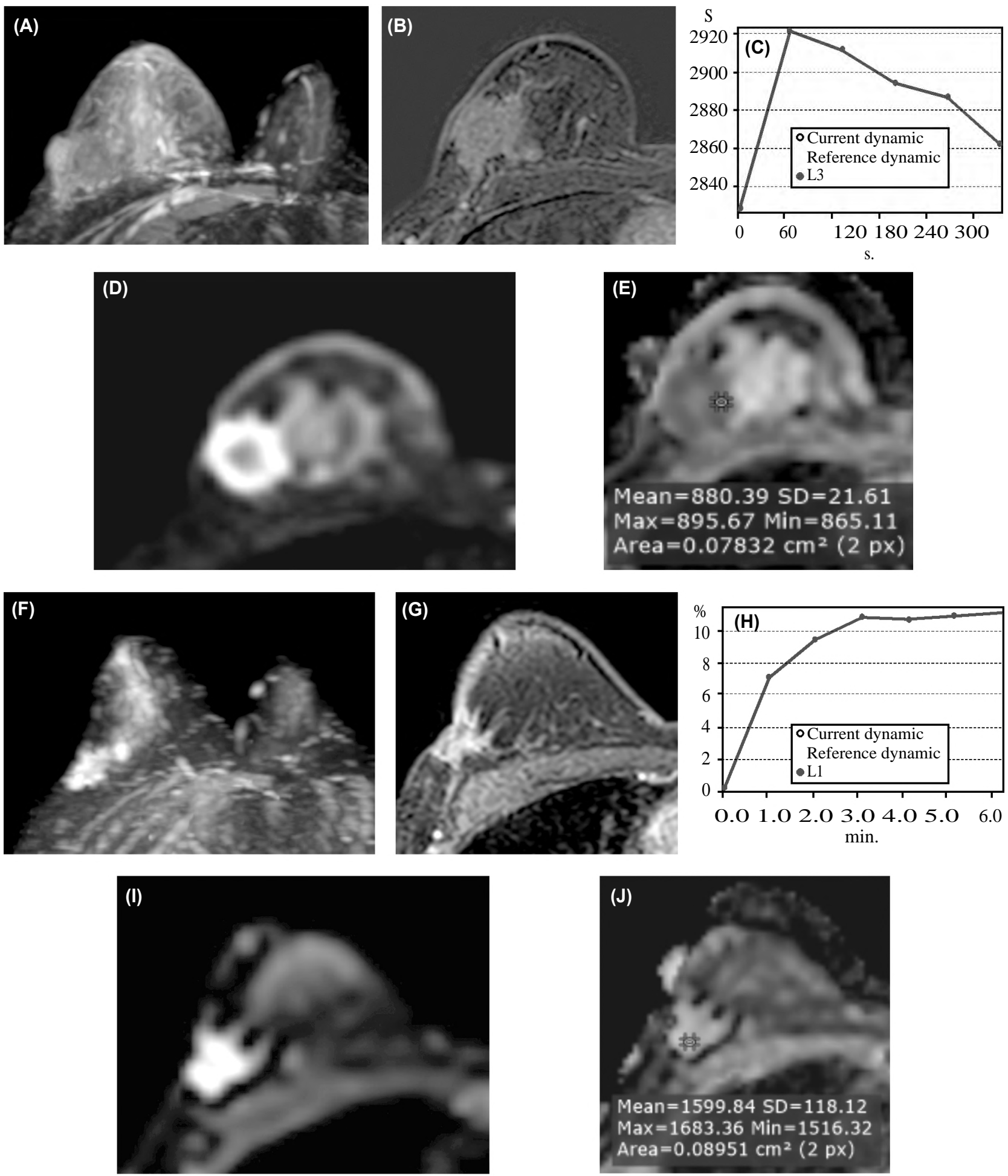

Fig. (2): Female patient, 30 years old, with right breast cancer (Pathologically proven infiltrating duct carcinoma) received NAC:

- MRI before NAC (2a-2e): Spiculated, heterogeneously enhancing fungating mass in right upper quadrant:

- 2a: MIP image of the lesion. 2b: Subtraction contrast-enhanced image. 2c: Time signal intensity curve of the mass showing type III (washout) curve. 2d: DWI, 2e: ADC map show restricted diffusion.

= MRI post NAC follow up (2f-2j):

- 2f: MIP image of the lesion. 2g: subtraction contrast-enhanced image showed decreased size of the mass. 2h: Time signal intensity curve of the mass showing type II (plateau) curve. 2i: DWI showed high signal of the lesion, 2j: ADC map showed higher signal with higher ADC value.

- MRI diagnosis: Partial response to therapy coping with histopathological diagnosis. 


\section{Discussion}

In this study all patients underwent "Tru-cut" biopsy before the NAC administration for the diagnosis of the pathological type. The most common pathological type of breast cancer in this study is the "invasive duct carcinoma" detected in twenty six patients (65\% of cases). This was in agreement with many prospective and retrospective studies [7-9]

In the current study, MRI results revealed complete response to the NAC in $20 \%$ of cases, partial response in $62.5 \%$, stable course in $5 \%$ of cases and progressive course in $12.5 \%$ of cases. While on pathological assessment following the NAC, $27.5 \%$ showed complete response, $57.5 \%$ showed partial response, $15 \%$ revealed no response. These results matched with those of previous studies [1013]. In a study conducted by Gezer et al., [38] patients were examined after administration of NAC with a diagnosis of locally advanced breast cancer, complete response was revealed in $13.2 \%, 73.7 \%$ of patients showed partial response, $10.5 \%$ of cases were diagnosed to have stable course, and 1 casewith progressive course. While on Pathology of the same study, 6 cases (15.8\%) showed complete response, 28 cases $(73.7 \%)$ showed partial response, 3 cases $(7.9 \%)$ showed stable course, and 1case (2.6\%) showed progressive course [12]. In Abedi et al. study, [11] that was conducted on 20 patients of locally advanced breast cancer cases to evaluate the validity of MRI in evaluation of tumor response to NAC, dynamic MRI showed complete response in 3 patients, partial response in 13 patients, stable disease in 3 patients, and progressive disease in 1 of the patients.

On dynamic MRI in this study, mass lesions (including focal, or decentralized lesions) were detected in 28 patients $(70 \%)$, while non mass lesions were detected in 6 patients $(15 \%)$. Four patients $(10 \%)$ showed no residual masses. Tiny foci were detected in two patients $(5 \%)$. This matched with Gezer et al. [12] who reported a wide variation in the morphology of the lesions on the dynamic MRI study. Moreover, in agreement with the results of Gezer et al., [12] the most common pattern of enhancement in this study was heterogeneous enhancement, it was detected in $68.4 \%$ of the cases.

In our study, the assessment of the response to the NAC with MRI revealed sensitivity of $91.2 \%$, specificity of $66.7 \%$ and accuracy $87.5 \%$. These results was in agreement with De Los Santos et al., aretrospective study conducted on 746 women with locally advanced breast cancer receiving NAC, who reported sensitivity of $92 \%$ and specificity $50 \%$ [14]. Also, similar validity was reported in Abedi et al., results, who found accuracy of $85 \%$ for MRI with sensitivity of $100 \%$ and specificity of $50 \%$ [11]. A retrospective study was conducted on 61 patientswith locally advanced breast cancer after NAC with a mean age of 56 years, and reported an accuracy of $84 \%$, a sensitivity of $86 \%$, a specificity of $79 \%$ for MRI evaluation of complete response [15]

The difference in sensitivity and specificity from other studies might be related to small sample size. Also, MRI could show the residual tumor with a high sensitivity $(100 \%)$ and an intermediate specificity $(50 \%)$ due to some discrepancy between the MRI size measurement, and histologic reports [11].

Our results were not matched with Schott et al., study apart from the accuracy which was nearly close to ours), who reported MRI sensitivity of $25 \%$ and specificity of $97 \%$.

In our study, there was two cases of underestimation "False negative results" in which there were no significant lesions on MRI and were reported as a complete responders radiologically. These two cases on histopathological examination showed residual millimetric foci. This agreed with Gezer et al., [12] who stated that it should be kept in mind that pathology accepts the tumor size as the entire width of the lesion, therefore, in patients with millimeteric tumor foci, pathology determines a larger tumor size than MRI. Also, In some patients, there might be no contrast enhancement on MRI while a few invasive cells might be detected on pathology. It is difficult to determine the actual size of the tumor in lesions with originally multiple nodular contrast enhancements that show partialpatchy response after NAC.

Underestimation of the tumor in MRI in cases of NAC administration may be due to antivascular effects of the NAC (resulting in less tumor enhancement), lack of inflammatory response surrounding the tumor in docetaxel-receiving patients, more extensive ductal carcinoma in situ components, and partial volume effects in very small foci of residual disease [18]. Underestimation of residual disease could lead to positive resection margins with viable residual tumor cells, necessitating resurgery. In addition, positive resection margins are associated with an increased long-term risk of disease recurrence in patients who have undergone breast-conserving surgery [17] 
MR imaging can underestimate residual disease when fragmentation occurs and small foci of residual tumor cells are scattered over a large area or overestimate residual disease if there is host response of reactive inflammation and fibrosis within the treated tumor bed $[\mathbf{1 8 , 1 9 ]}$. Also our results agreed with Shin et al., [10] study where MRI underestimated the size of the residual tumor in $7 \%(3 / 43)$ of patients and overestimated it in 19\% (8/43).

On the other hand, in our study, MRI showed overestimation in 7 cases compared to the pathology, 4 cases of them reported partial response on MRI and complete response on pathology, 1 case of progressive course on MRI and partial response on pathology and 1 case of stable course in MRI and partial response on pathology. This was in agreement with Diguisto et al., [20] where for 19 women, among 30 women of pathological complete response, the MRI concluded that there was residual tumor, while in fact the pathological response was complete.

\section{Conclusion:}

MRI proved to be of highly beneficial in assessment of response of locally advanced breast cancer to NAC. However, it may overestimate or underestimate residual disease in some patients. Further studies with larger number of patients areneeded for more meticulous assessment of the specificity of MRI.

\section{References}

1- ASLAM H.M., SALEEM S., SHAIKH H.A., SHAHID N., MUGHAL A. and UMAH R.: Clinico-pathological profile of patients with breast diseases. Diagnostic Pathology, 8 (1), 2013.

2- JANSEN S.A., FAN X., KARCZMAR G.S., ABE H., SCHMIDT R.A. and NEWSTEAD G.M.: Differentiation between benign and malignant breast lesions detected by bilateral dynamic contrast-enhanced MRI: A sensitivity and specificity study. Magnetic Resonance in Medicine, 59 (4): 747-54, 2008.

3- BERRY D.A., CRONIN K.A., PLEVRITIS S.K., FRYBACK D.G., CLARKE L., ZELEN M., et al.: Effect of Screening and Adjuvant Therapy on Mortality from Breast Cancer. New England Journal of Medicine, 353 (17): 1784-92, 2005.

4- CHAGPAR A.B., MIDDLETON L.P., SAHIN A.A., DEMPSEY P., BUZDAR A.U., MIRZA A.N., et al.: Accuracy of Physical Examination, Ultrasonography, and Mammography in Predicting Residual Pathologic Tumor Size in Patients Treated With Neoadjuvant Chemotherapy. Annals of Surgery, 243 (2): 257-64, 2006.

5- BHATTACHARYYA M., RYAN D., CARPENTER R., VINNICOMBE S., GALLAGHER C.J.: Using MRI to plan breast-conserving surgery following neoadjuvant chemotherapy for early breast cancer. British Journal of Cancer, 98 (2): 289-93, 2008.
6- GOLSHAN M., FUNG B.B., WILEY E., WOLFMAN J., RADEMAKER A. and MORROW M.: Prediction of breast cancer size by ultrasound, mammography and core biopsy. The Breast, 13 (4): 265-71, 2004.

7- CHEN J-H., BAHRI S., MEHTA R.S., KUZUCAN A., YU H.J., CARPENTER P.M., et al.: Breast Cancer: Evaluation of Response to Neoadjuvant Chemotherapy with 3.0-T MR Imaging. Radiology, 261 (3): 735-43, 2011.

8- LYOU C.Y., CHO N., KIM S.M., JANG M., PARK J-S., BAEK S.Y., et al.: Computer-Aided Evaluation of Breast MRI for the Residual Tumor Extent and Response Monitoring in Breast Cancer Patients Receiving Neoadjuvant Chemotherapy. Korean Journal of Radiology, 12 (1): 34, 2011.

9- HYLTON N.M., BLUME J.D., BERNREUTER W.K., PISANO E.D., ROSEN M.A., MORRIS E.A., et al.: Locally Advanced Breast Cancer: MR Imaging for Prediction of Response to Neoadjuvant Chemotherapy-Results from ACRIN 6657/I-SPY TRIAL. Radiology, 263 (3): 663-72, 2012

10- SHIN H.J., KIM H.H., AHN J.H., KIM S.B., JUNG K.H., GONG G., et al.: Comparison of mammography, sonography, MRI and clinical examination in patients with locally advanced or inflammatory breast cancer who underwent neoadjuvant chemotherapy. The British Journal of Radiology, 84 (1003): 612-20, 2011.

11- ABEDI M., FARROKH D., HOMAEI F.S., JOULAEE A., ANBIAEE R., ZANDI B., et al.: The validity of MRI in evaluation of tumor response to neoadjuvant chemotherapy in locally advanced breast cancer. Iranian journal of cancer prevention, 6 (1): 28, 2013.

12- GEZER N.S., ORBAY O., BALCI P., DURAK M.G., DEMIRKAN B. and SAYDAM S.: Evaluation of Neoadjuvant Chemotherapy Response with Dynamic Contrast Enhanced Breast Magnetic Resonance Imaging in Locally Advanced Invasive Breast Cancer. The Journal of Breast Health, 10 (2): 111-8, 2014.

13- MUKHERJEE P., SHARMA S., SHEIKH Z. and VIJAYKUMAR D.: Correlation of clinico-pathologic and radiologic parameters of response to neoadjuvant chemotherapy in breast cancer. Indian journal of cancer, 51 (1): 25 , 2014.

14- De LOS SANTOS J., BERNREUTER W., KEENE K. KRONTIRAS H., CARPENTER J., BLAND K., et al.: Accuracy of Breast Magnetic Resonance Imaging in Predicting Pathologic Response in Patients Treated With Neoadjuvant Chemotherapy. Clinical Breast Cancer, 11 (5): 312-9, 2011.

15- CROSHAW R., SHAPIRO-WRIGHT H., SVENSSON E., ERB K. and JULIAN T.: Accuracy of Clinical Examination, Digital Mammogram, Ultrasound, and MRI in Determining Postneoadjuvant Pathologic Tumor Response in Operable Breast Cancer Patients. Annals of Surgical Oncology, 18 (11): 3160-3, 2011

16- SCHOTT A.F., ROUBIDOUX M.A., HELVIE M.A., HAYES D.F., KLEER C.G., NEWMAN L.A., et al.: Clinical and Radiologic Assessments to Predict Breast Cancer Pathologic Complete Response to Neoadjuvant Chemotherapy. Breast Cancer Research and Treatment, 92 (3): 231-8, 2005. 
17- DENIS F., DESBIEZ-BOURCIER A.V., CHAPIRON C., ARBION F., BODY G. and BRUNEREAU L.: Contrast enhanced magnetic resonance imaging underestimates residual disease following neoadjuvant docetaxel based chemotherapy for breast cancer. European Journal of Surgical Oncology (EJSO), 30 (10): 1069-76, 2004.

18- COWEN D., HOUVENAEGHEL G., BARDOU V-J., JACQUEMIER J., BAUTRANT E., CONTE M., et al. Local and distant failures after limited surgery with positive margins and radiotherapy for node-negative breast cancer. International Journal of Radiation Oncology Biology Physics, 47 (2): 305-12, 2000.
19- WASSER K., SINN H., FINK C., KLEIN S., JUNKERMANN H., LÜDEMANN H., et al.: Accuracy of tumor size measurement in breast cancer using MRI is influenced by histological regression induced by neoadjuvant chemotherapy. European Radiology, 13 (6): 1213-23, 2003.

20- DIGUISTO C., OULDAMER L., ARBION F., VILDE A and BODY G.J.Ar.: MRI evaluation of residual breast cancer after neoadjuvant chemotherapy: Influence of patient, tumor and chemotherapy characteristics on the correlation with pathological response, 35 (1): 581-5, 2015 . 


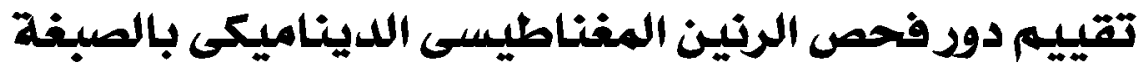

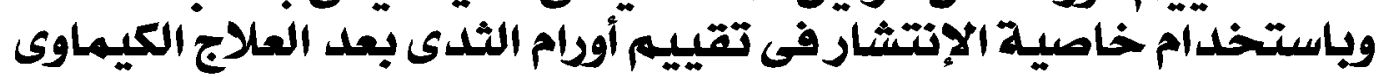

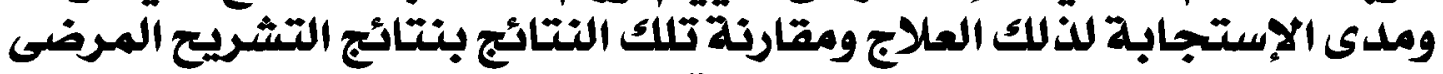 كهرجع قياسى}

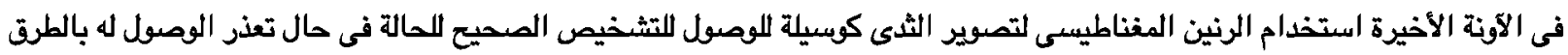

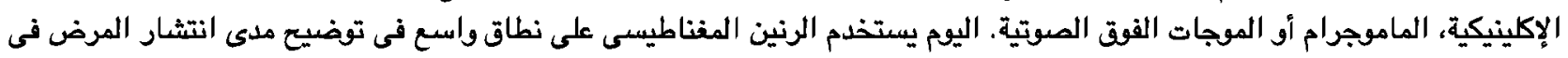
مرضى سرطان الثىى.

يستخدم الرنين المفناطيسى الديناميكى باستخدام الصبفة في توصيف الإصابة بالثدى، فهو يستطيع أن يميز الإصابة الحميدة من الخبيثة

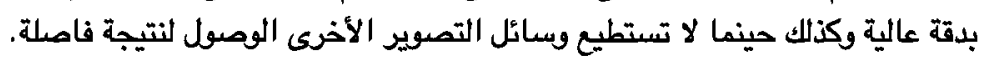

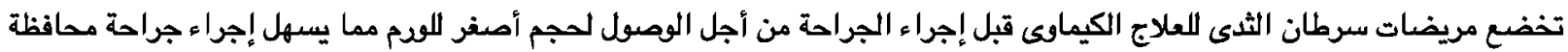

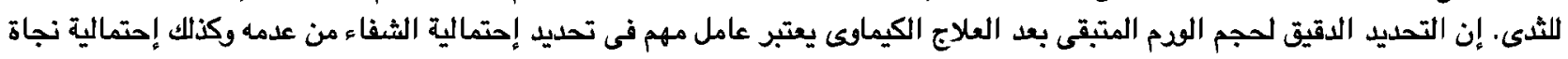

إن التوصيف الخاطئ لحجم الوم المتبقى بعد العلاج الكيماوى بنسبة أكبر مما هو عليه بالفعل يؤدى إلى إطالة فترة العلاج أواستئصسال

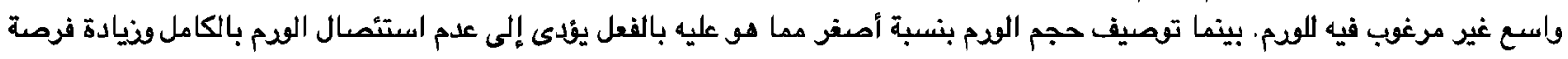
الإنتكاسة بعد الخضوع اللجراحة.

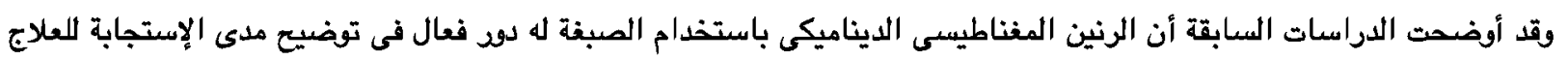

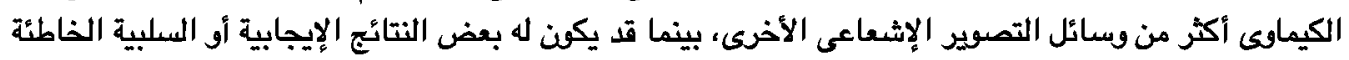

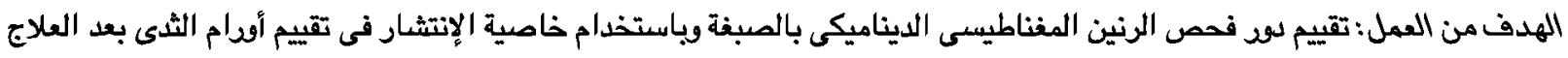

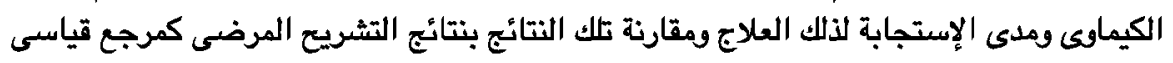
خطة البحث: تمت هذه الدراسة على أربعين مريضة بسرطان الثى بمعل أربعين ودم. تم اختيار المرضى على أساس هذه القواعد:

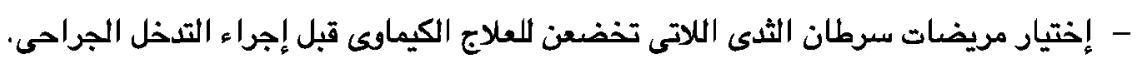

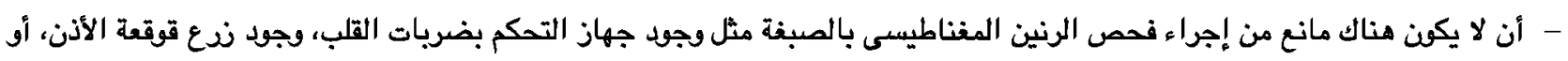

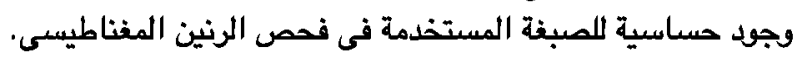
كل المرضى خضعوا لفحص الرنين المغناطيسى على النحو التالى: - فحص الرنين المغناطيسى العادى بدون مبغئة.

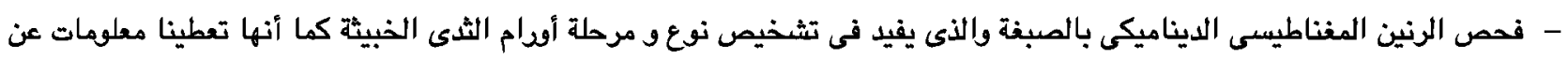

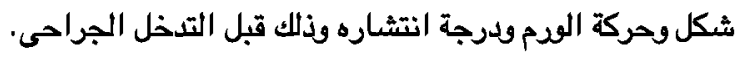

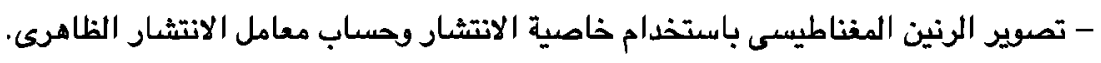

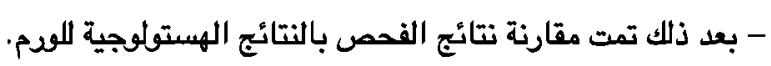

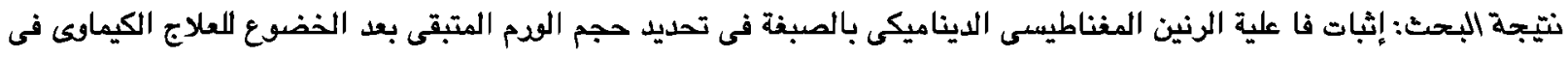

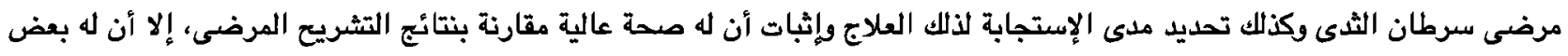

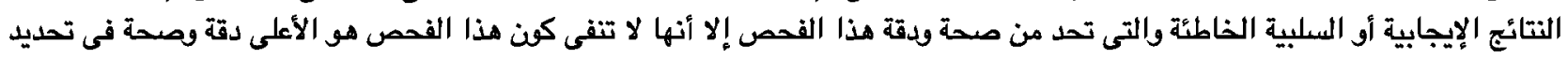

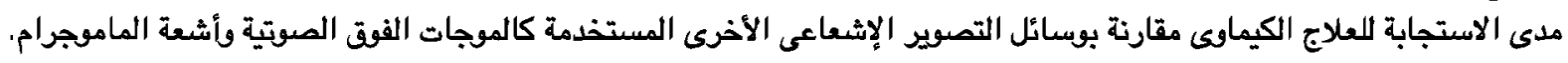

